\title{
Protective Effect of Lactobacillus fermentum on Lead-induced Hematological and Body Weight Alterations in Rats
}

\author{
Elham Ghazanfarpour ${ }^{1}(\mathbb{D})$, Mahnoosh Fatemi*2 $^{(D)}$, Fereshte Ghandehari1 $^{1}$ \\ 1. Department of Microbiology, Falavarjan Branch, Islamic Azad University, Isfahan, Iran. \\ 2. Department of Biology, Falavarjan Branch, Islamic Azad University, Isfahan, Iran.
}

\begin{tabular}{l}
\hline Article Info \\
\hline Article Type: \\
Original Research \\
\hline Article History: \\
Received: 05.05.2019 \\
Accepted: 01.07.2019 \\
\\
\hline *Corresponding Author: \\
Mahnoosh Fatemi \\
Department of Biology, Falavarjan \\
Branch, Islamic Azad University, \\
Isfahan, Iran. \\
E-mail: mehr.fatemi7@gmail.com
\end{tabular}

A B S T R A C T

Background:

Lead is known to be a highly toxic heavy metal which has a wide range of effect on human health. It has been proven that probiotics are able to bind heavy metals and remove them from the environment. In this study, the effect of Lactobacillus fermentum (L. fermentum) and its cytoplasmic extract were investigated on the hematological and body weight parameters in lead exposed rats.

\section{Methods:}

Forty eight rats were divided into 6 groups of eight as follows: Group 1: controls; Group 2: treated with lead acetate; Group 3: treated with $L$. fermentum; Group 4: treated with lead acetate and intact L. fermentum bacteria; Group 5: treated with the extracts of L. fermentum; Group 6: treated with lead acetate and the extract. At the completion of the experiments, rats' blood samples were collected and analyzed for the hematological parameters. The lead concentrations were measured in the fecal pellets.

\section{Results:}

The results demonstrated significant differences among the hematological parameters in groups 2 and 6, compared with those in the controls. However, no significant differences were detected for the parameters in groups 3, 4 and 5. The lead concentrations in the fecal pellets of group 4 animals showed a significant increase compared to those recorded for the groups that were exposed to lead acetate.

\section{Conclusion:}

The findings suggest that L. fermentum may inhibit or minimize the harmful effects of lead on rat's hematological parameters by binding to the heavy metal and removing it from the body.

Keywords:

Hematological Parameters, L. Fermentum, Lead Toxicity, Rats.

How to cite this paper

Ghazanfarpour E, Fatemi M, Ghandehari F. Protective Effect of Lactobacillus fermentum on Lead-induced Hematological and Body Weight Alterations in Rats. Iran J Toxicol. 2019; 13 (3): 15-20

\section{INTRODUCTION}

Probiotics are bacterial organisms that provide health benefits to the host when administered in adequate amounts (1). These micro-organisms are useful organisms and parts of the normal flora in the gastrointestinal (GI) tract (2). Two major groups of probiotics are Lactobacillus and Bifidobacteria. Their most important activities in the GI tract are antagonistic effects, enhancement of digestion, supporting the immune system and stimulating the vitamin production ( $\underline{3})$. Recently, it has been found that these bacteria have the capacity to bind heavy metals and remove them from the internal environment ( 4 ). Therefore, they could be an appropriate intervention for the biological removal of heavy metals. The plasma membranes of these Gram-positive bacteria are covered with a thick layer of peptidoglycans, lipoteichoic acids, proteins and polysaccharides (ㅁ). These structural elements contain various charged moieties, such as carboxyl, hydroxyl and phosphate groups. These moieties possess numerous potential ligands capable of binding cationic ions, like lead and cadmium (ㅁ). Lead is one of the most toxic heavy metals, which is used frequently in many industrial products, such as airplanes, batteries, ammunitions, 
ceramics and plastics (ㄱ). Since lead is capable of entering the body through the skin, respiratory system and orally, it can readily accumulate in various tissues and organs, leading to pathologic conditions $(\underline{8,9})$. Therefore, it is imperative to explore effective and practical approaches to promote the removal of this harmful heavy metal from the body. This study assumed that the removal of lead from the body may have a similar mechanism as its removal from the environment. The aim of this study was to investigate the protective effects of Lactobacillus fermentum ( $L$. fermentum) and its cytoplasmic extract on the hematological and body weight parameters of rats exposed to lead acetate.

\section{MATERIALS AND METHODS}

Animals and Treatments: Forty eight female rats $(150 \pm 20 \mathrm{~g})$ were purchased from Tehran University's Animal Holding Department. Rats were kept under standard healthy laboratory conditions, using $12 \mathrm{~h}$ of light and $12 \mathrm{~h}$ of dark cycle at $23 \pm 2^{\circ} \mathrm{C}$ and $45 \%$ humidity. Food and water were provided ad libitum. After a week of adaptation to the new environment, rats were randomly divided into six groups:

Group 1: controls; they were fed normal food and water plus oral administration of $1 \mathrm{ml}$ physiologic serum for eight weeks.

Group 2: were administered $L$. fermentum orally $\left(1.5 \times 10^{8} \mathrm{CFU} / \mathrm{ml}\right)$ for eight weeks $(\underline{10})$.

Group 3: were administered the cytoplasmic extracts of L. fermentum $(2000 \mu \mathrm{g} / \mathrm{ml})$ for eight weeks.

Group 4: were orally administered lead acetate (500 $\mathrm{mg} / \mathrm{kg}$ ) for eight weeks (11).

Group 5: were orally given L. fermentum $\left(1.5 \times 10^{8} \mathrm{CFU} / \mathrm{ml}\right)$ and lead acetate $(500 \mathrm{mg} / \mathrm{kg})$ simultaneously for eight weeks.

Group 6: were treated orally L. fermentum cytoplasmic extracts $(2000 \mu \mathrm{g} / \mathrm{ml})$ and lead acetate $(500 \mathrm{mg} / \mathrm{kg})$ for eight weeks.

Ethical Considerations: The ethical guidelines on the use of laboratory animals for research were observed, as approved by the Institutional Review Board of the Islamic Azad University at Flavarjan campus, Flavarjan, Isfahan (Certificate No: IR.IAU.FALA.REC.1396.012).

\section{Cultivation and Preparation of Bacterial} Cytoplasmic Extract: The strain L. fermentum (PTCC 1638) was obtained from Persian Type Culture Collection (Code Number: I 124) and was inoculated in $1 \mathrm{ml}$ distilled water then was cultured in De Man, Rogosa and Sharpe agar (MRS) culture media, and was incubated at $37^{\circ} \mathrm{C}$ for $24 \mathrm{hr}$. The bacterial cytoplasmic extract was prepared using freeze-thaw methods $(\underline{12})$. The bacterial culture was centrifuged at
$3000 \mathrm{rpm}$ for $15 \mathrm{~min}$ and the supernatant was discarded. Phosphate buffered saline $(1.5 \mathrm{ml})$ was added to the sediment and centrifuged again at 3000 rpm for $10 \mathrm{~min}$. These samples were placed in liquid nitrogen $\left(-196^{\circ} \mathrm{C}\right)$ for $5 \mathrm{~min}$, then placed at $37^{\circ} \mathrm{C}$ for 5 min and centrifuged at $12000 \mathrm{rpm}$ for $30 \mathrm{~min}$. The supernatants were collected as the cytoplasmic extract and were administered orally to Groups 3 and 6. The cytoplasmic extract protein concentrations were measured by Bradford method ( $\underline{13})$. Several colonies of L. fermentum were transferred into MRS agar culture media and mixed well. These samples were designated as L. fermentum bacterial suspension. This suspension was equivalent to 0.05 McFarland standards $\left(1.5 \times 10^{8}\right.$ $\mathrm{CFU} / \mathrm{ml}$ ) and was administered orally to animals in Groups 3 and 4.

Evaluation of Hematological Parameters: At the completion of the treatments, rats were anesthetized by intraperitoneal injection of ketamine $(50 \mathrm{mg} / \mathrm{kg})$ and xylazine $(10 \mathrm{mg} / \mathrm{kg})$. Animals were then weighed and the blood samples were collected by puncturing their hearts. The blood samples were poured into test tubes, containing anticoagulant and the blood cells were counted, using an automated cell counter (XE2100, Sysmex, Kobe, Japan). The parameters determined were: white blood cells (WBC), red blood cells (RBC), mean corpuscular volume (MCV), mean corpuscular hemoglobin $(\mathrm{MCH})$, red blood cell distribution width (RDW), platelet (PLT), platelet distribution width (PDW), mean platelet volume (MPV), hemoglobin (HGB) and hematocrit (HCT). The RDW and PDW are standard measures of the range of variations of red blood cell and platelet volumes.

\section{Determination of Lead Concentration in Fecal}

Pellets: A 10mg sample of each rat's fecal pellets was transferred to a tube containing nitric and perchloric acids (at a ratio of $4: 1$ ). The fecal samples were heated for 24 hours to evaporate the excess acids. Then $10 \mathrm{ml}$ deionized water was added to each sample and the lead concentration was determined by inductively coupled plasma mass spectrometry (ICP-MS).

Statistical Analyses: Data were analyzed using SPSS software, version 20. One-way analysis of variance (ANOVA) was performed to obtain the differences in the means for the various tests among the groups. A significant difference was considered at $P<0.05$.

\section{RESULTS}

Hematological Parameters: As seen in Table 1, WBC in lead exposed rats were significantly elevated while there were no considerable differences in other blood parameters compared to those recorded for the controls. There was a significant reduction in MCV and MCH in the lead exposed group while no such changes were evident in other groups. Also, there was significant decreases in RBC, HGB and HCT for the rats that received both lead and the cytoplasmic extract of 
L. fermentum. However, similar changes were not noted in other groups as compared to those in the control group. While the PLT numbers decreased in lead exposed rats, those that were exposed to lead acetate and the cytoplasmic extracts did not show a significant difference in PLT numbers compared to that noted in the controls. The PDW did not change significantly in the experimental groups while MPV increased in the lead exposed rats compared to that for the controls. Lastly, no significant differences were observed in RDW in any of the groups.

Table 1. Changes in the hematologic parameters among the study groups.

\begin{tabular}{lllllll}
\hline \multicolumn{1}{c}{ Blood Element } & \multicolumn{1}{c}{$\begin{array}{c}\mathbf{1} \\
\text { (Controls) }\end{array}$} & \multicolumn{1}{c}{$\begin{array}{c}\mathbf{2} \\
\text { (Lead only) }\end{array}$} & \multicolumn{1}{c}{$\begin{array}{c}\mathbf{3} \\
(\mathrm{LF})\end{array}$} & $\begin{array}{c}\mathbf{4} \\
\text { (Lead + LF) }\end{array}$ & $\begin{array}{c}\mathbf{5} \\
\text { (Extract) }\end{array}$ & $\begin{array}{c}\mathbf{6} \\
(\mathrm{Lead}+\mathrm{Ext})\end{array}$ \\
\hline WBC $\left(10^{3} / \mathrm{mm}^{3}\right)$ & $8.6 \pm 1.3$ & $12.3 \pm 1.5^{\Omega}$ & $8.2 \pm 1.3$ & $10.8 \pm 1.2$ & $9.7 \pm 1.9$ & $10 \pm 1.8$ \\
RBC $\left(10^{6} / \mathrm{mm}^{3}\right)$ & $7.1 \pm 0.6$ & $6 \pm 0.6^{*}$ & $7.0 \pm 0.3$ & $7.2 \pm 0.3$ & $7.1 \pm 0.6$ & $6.2 \pm 0.9^{*}$ \\
HGB $\left(\mathrm{g} / \mathrm{dl}^{-1}\right)$ & $13.4 \pm 0.7$ & $10.8 \pm 1.1^{\S}$ & $12.7 \pm 0.4$ & $12.4 \pm 0.3$ & $13 \pm 0.8$ & $10.9 \pm 1.8^{\Omega}$ \\
HCT $(\%)$ & $40.8 \pm 2.3$ & $32.7 \pm 3.9 \S$ & $39.5 \pm 1.5$ & $37.9 \pm 1.0$ & $39.9 \pm 2.5$ & $33.7 \pm 4.0 \S$ \\
MCV $\left(\mu \mathrm{m}^{3}\right)$ & $56.2 \pm 3.9$ & $51.4 \pm 1.3^{*}$ & $56 \pm 2.9$ & $54.5 \pm 1.5$ & $56.1 \pm 2.5$ & $52.6 \pm 2.2^{*}$ \\
MCH $(\mathrm{pg})$ & $18.4 \pm 0.8$ & $17.3 \pm 0.5^{*}$ & $18.7 \pm 0.7$ & $17.9 \pm 0.2$ & $18.3 \pm 0.7$ & $17.3 \pm 0.7^{*}$ \\
RDW $(\%)$ & $15.8 \pm 1.3$ & $13.8 \pm 1.0$ & $14.4 \pm 0.4$ & $14.3 \pm 0.8$ & $14.4 \pm 2.2$ & $14.1 \pm 2.1$ \\
PLT $\left(10 \% / \mathrm{mm}^{3}\right)$ & $120 \pm 9.2$ & $238.3 \pm 5.2^{\S}$ & $94.3 \pm 8.4$ & $52.1 \pm 7.0$ & $183 \pm 8.6$ & $70.8 \pm 4.4 \S$ \\
PDW $(\%)$ & $8.3 \pm 0.5$ & $8.6 \pm 0.7$ & $8.4 \pm 0.8$ & $8.4 \pm 0.6$ & $8.4 \pm 1.1$ & $8.1 \pm 0.7$ \\
MPV $\left(\mu \mathrm{m}^{3}\right)$ & $6.6 \pm 0.3$ & $8.2 \pm 1.2^{\Omega}$ & $7.1 \pm 0.3$ & $7.4 \pm 0.5$ & $6.9 \pm 0.4$ & $7.3 \pm 0.6$ \\
\hline
\end{tabular}

$\mathrm{LF}=$ L. fermentum; Ext = Cytoplasmic extract. The significance levels were: ${ }^{*} \mathrm{p}<0.05,{ }^{\Omega} \mathrm{p}<0.01$ and ${ }^{\mathrm{s}} \mathrm{p}<0.001$.

Data are shown as means \pm standard deviations. 1: Control group, 2: Lead exposed group, 3: L. fermentum group, 4: Lead + L. fermentum group, 5:

Cytoplasmic extract group, and 6: Lead + cytoplasmic extract group.

\section{Body Weight Changes in Experimental Groups:}

As shown in Figure 1, there was a significant reduction in body weight of animals that were exposed to lead acetate $(\mathrm{P}<0.001)$ or bacterial extract alone $(\mathrm{P}<0.05)$, or to both treatments simultaneously $(\mathrm{P}<0.001)$, compared to those noted in the controls. There was an insignificant decline in body weight of rats treated with L. fermentum and those treated with both lead acetate and L. fermentum, as compared to those in the control group.

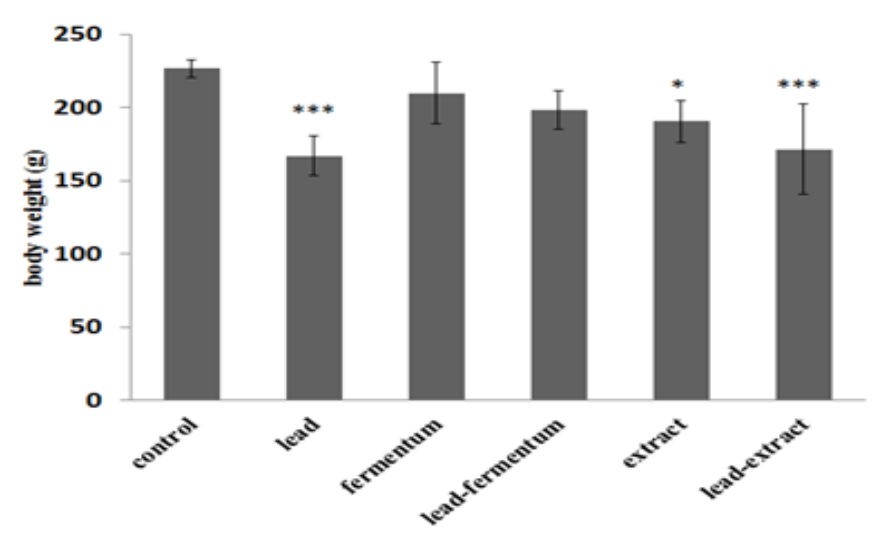

Figure 1. Body weight changes in the study rats. The significance levels were: ${ }^{*} \mathrm{p}<0.05 ;{ }^{* *} \mathrm{p}<0.01$ and ${ }^{* * *} \mathrm{p}<0.001$. Data are shown as means \pm standard deviations.

Lead Concentrations in Fecal Pellets: As shown in Figure 2, the lead concentrations in the fecal pellets increased significantly $(\mathrm{P}<0.001)$ in the lead exposed rats, and those treated with both lead and L. fermentum or the cytoplasmic extract, compared to those in the controls. There was not considerable differences between the fecal lead concentrations of the rats exposed to lead and were treated with either the intact bacteria or the cytoplasmic extract.

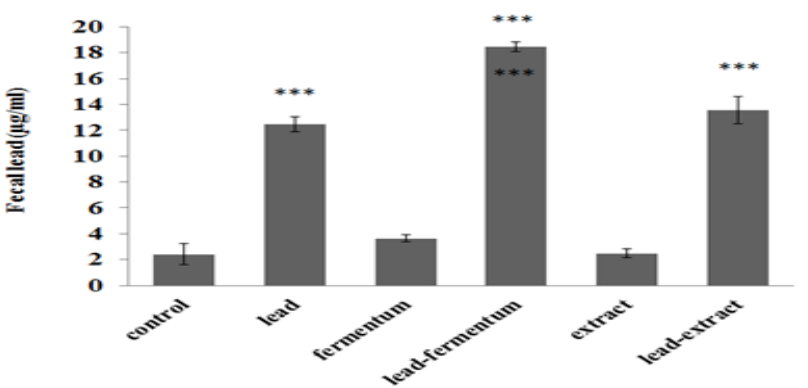

Figure 2. Fecal lead concentrations in the study rats. The significance levels were: ${ }^{*} \mathrm{p}<0.05 ;{ }^{* *} \mathrm{p}<0.01$ and ${ }^{* * *} \mathrm{p}<0.001$. Data are shown as means \pm standard deviations. Asterisks above the bar graphs denote significance difference compared to the controls. Asterisks inside the bar graph representing Group 4 indicate significance difference compared to groups exposed to lead acetate and treated with $L$. fermentum or the cytoplasmic extract.

\section{DISCUSSION}

Safety \& Protective Effects of L. fermentum and its Extract: This study was conducted to investigate the protective effects of $L$. fermentum in rats exposed to lead acetate as a toxicant. The data derived from the hematological tests and body weights suggest that the oral administration of $L$. fermentum is safe in rats, since it did not cause any demonstrable or harmful effect (Figure 1 \& Table 1). Consistent with our findings, other studies have also reported that the oral administration of L. acidophilus, Bifidobacterium, acidophilus pedioccocous and Bacillus subtilis had no detrimental effects on the hematological parameters of animals, such as mice, tilapia rainbow trout and Clarias gariepinus juveniles catfish (14-18). Taken together, these findings imply that L. fermentum is safe in rats since they do not seem to multiply in the animals' blood. Further evidence in support of the protective effect comes from the observation that the probiotic bacteria appear to inhibit the toxic effect of lead acetate in the same animals. One of the benefits of probiotics is to strengthen the immune system ( $\underline{3})$. This was evident in Groups 4 and 6, where the probiotic bacteria or the 
cytoplasmic extract were present and partially inhibited the toxic effects of the lead acetate in the animals, as compared to that observed in Group 2 that received lead acetate only.

\section{Lead Acetate Toxicity Effects}

Effect on White Blood Cells: The observation that the WBCs were significantly increased in rats exposed to lead acetate indicates that the compound is likely to cause an inflammatory response in the body by stimulating the immune system toward the proliferation of WBC. Previous studies $(\underline{19,20})$ have reported leukocytosis in female mice and rats in response to lead compounds. WBC showed a slight increase in the lead exposed groups that were treated with either intact L. fermentum or the extract compared to the control group. However, increase was not statistically significant.

Effects on Red Blood Cells \& Hemoglobin: We observed a considerable reduction on the number of RBCs in response to lead acetate (Table 1), suggesting that lead causes anemia by impairing the biosynthesis of heme ( $\underline{21})$ and erythropoietin (22). Both of these molecules play important roles in the formation of erythrocytes. However, there were no significant changes in the number of RBCs in the experimental groups that were treated with lead acetate and $L$. fermentum or the extract. Further, lead acetate likely decreased the HGB concentration by inhibiting $\delta$ aminolevulinic acid dehydratase and ferrochelatase enzymes, both of which involved in the biosynthesis of heme (22). Our findings suggest that the intact $L$. fermentum but not the extract, is able to inhibit the adverse effects of lead on factors involved in the formation and proliferation of RBCs (Table 1, Group 4 vs Group 6) in the bone marrow $(\underline{23,24})$.

Effects on Other Hematologic Parameters: The HCT levels, the ratio of RBCs volume to the total blood volume, decreased significantly in lead exposed animals (Groups 4 \& 6) while there were no significant changes in other groups, compared to the controls. Consistent with our findings, another study (24) has reported significant decreases in HGB and HCT levels in rats exposed to high lead concentrations. It is already known that lead contributes to a reduction in the number of reticulocytes and erythrocytes in experimental animals ( $\underline{23})$. The findings also revealed significant decreases in the levels of MCV and MCH in the lead exposed rats (Group 2) and those exposed to both lead and the cytoplasmic extract (Group 6). This was not the case when intact bacteria and lead were both present in the culture media (Group 4). Decreases in MCV and MCH parameters in response to lead exposure have been reported previously by multiple studies $(\underline{20,21,24,25})$. These findings clearly suggest that the intact bacteria, but not the extract, are capable of providing protection against the adverse effects of lead on MCV and MCH parameters. Interestingly, the RDW parameter changed insignificantly across the experimental groups compared to the controls. This may suggest that lead acetate, especially at the concentrations used in this study, did not contribute significantly to the RBCs width.

In the absence of lead acetate, the intact bacteria were associated with a $22 \%$ decrease in the PLT numbers while there was a $50 \%$ increase in PLT when only the extract was present in the animals. However, the PDW did not show significant variations across the experimental groups, compared to that in the controls. This finding suggests that neither lead acetate nor the intact bacteria or the extract, at the concentrations used, caused significant changes in the PLT width. In the presence of lead acetate, both the intact bacteria and the extract were associated with approximately a $42 \%$ decrease in the PLT numbers in the culture media. Under this condition, the PLT numbers doubled while the MPV increased by $24 \%$. A previous study (24) has suggested that the reduction in platelet formation in the bone marrow in response to lead exposure results in the production of larger platelets. However, the MPV did not show a significant change across all other experimental groups, compared to that noted in the controls.

Effects on Body Weight: As shown in Figure 1, there was a significant reduction in body weight of the animals that were exposed to lead acetate $(\mathrm{P}<0.001)$ or bacterial extract alone $(\mathrm{P}<0.05)$, or to both treatments simultaneously $(\mathrm{P}<0.001)$, compared to those for the control group. There was an insignificant decline in body weight of rats treated with intact $L$. fermentum and those treated with both lead acetate and $L$. fermentum, compared to the control group. The adverse effects of lead on body weight might be due to interruption in food ingestion, appetite and/or food lost through anorexia or both $(\underline{26,27})$. The findings suggest that the intact $L$. fermentum may protect significantly against the adverse effects of lead toxicity on the body weight while the extract is not as effective.

Lead Concentrations in Fecal Pellets: The fact that lead at significantly increased concentrations, compared to the controls, were detected in the fecal pellets of the lead treated rats after administration of the intact bacteria (Group 4) or the extract (Group 6), suggests that L. fermentum or the extract greatly helped in the excretion of lead from the animals' body. These findings are consistent with those reported by previous studies $(\underline{28,29})$. The significantly greater amounts of lead detected in the fecal pellets in Groups 4 and 6, compared to that measured in Group 2 (lead acetate only) suggest that the probiotic bacteria and the extract might have inhibited the absorption of lead by the gastrointestinal tract. Our notion is in agreement with those reported by previous studies for the effects of $L$. fermentum bacteria on the removal of lead, cadmium and copper from the body of aquatic animals $(\underline{30,31})$.

In summary, our study findings suggest that lead, as a divalent cation, binds to the anionic moieties in the cell wall structures of L. fermentum bacteria, and is removed from the intestinal tract. In other words, the bacteria act similarly to chelating agents, used clinically to treat cases of poisoning with heavy metals. Further studies are required to elucidate the exact biochemical 
mechanisms involved in the removal of lead and other toxic heavy metals.

\section{CONCLUSIONS}

The present study has shown that L. fermentum has no detrimental effect on hematological parameters and body weight. The probiotic bacteria potentially inhibit the harmful effects of lead on the blood parameters and body weight in experimental animals. It is highly likely that these bacteria bind lead ions and remove this heavy and toxic metal from the body. This putative mechanism is believed to be operational by the intact bacteria and, to a lesser extent, the cytoplasmic extract alike. We recommend further studies conducted on the cellular and molecular mechanisms involved in the interaction of $L$. fermentum and the extract with toxic heavy metals, such as lead, that are prevalent in the environment.

\section{ACKNOWLEDGEMENT}

This article was extracted from a master's thesis project in microbiology, conducted by Ms. Elham Ghazanfarpour, and supervised by Dr. Fatemi and Dr. Ghandhari, at the Flavarjan campus of the Islamic Azad University, Flavarjan, Isfahan. We gratefully acknowledge the assistance of the University and the Department of Microbiology for providing the laboratories and equipment to conduct this study.

\section{CONFLICT OF INTEREST}

The authors declare no conflict of interest in the course of conducting this study.

\section{REFERENCES}

1. Bron PA, Kleerebezem M, Brummer RJ, et al. Can probiotics modulate human disease by impacting intestinal barrier function? British Journal of Nutrition. 2017;117:93-107.

2. Faujdar SS, Mehrishi P, Bishnoi S, et al. Role of probiotics in human health and disease: an update. International Journal of Current Microbiology and Applied Sciences. 2016;5:328-344.

3. Afify AE-MM, Romeilah RM, Sultan SI, et al. Antioxidantactivity and biological evaluations of probiotic bacteria strains. International Journal of Academic Research. 2012;4:131-139.

4. Mosa KA, Saadoun I, Kumar K, et al. Potential biotechnological strategies for the cleanup of heavy metals and metalloids. Frontiers in Plant Science. 2016;7:303

5. Zerbib D. Bacterial Cell Envelopes: Composition, Architecture, and Origin. Handbook of Electroporation. 2017:417-436.

6. Halttunen T, Salminen S, Tahvonen R. Rapid removal of lead and cadmium from water by specific lactic acid bacteria. International Journal of Food Microbiology. 2007;114:30-35.

7. Assi MA, Hezmee MNM, Haron AW, et al. The detrimental effects of lead on human and animal health. Veterinary World. 2016;9:660-671.
8. Fazli D, Malekirad AA, Mirzaee M, et al. Study on the link between lead exposure and hematological, psychological, and memorial parameters in automobile repair workers. Health. 2014;6:712-719.

9. Kim JH, Kang JC. Toxic effects on bioaccumulation and hematological parameters of juvenile rockfish Sebastes schlegelii exposed to dietary lead $(\mathrm{Pb})$ and ascorbic acid. Chemosphere. 2017;176:131-140.

10. Zhai Q, Tian F, Zhao J, Zhang H, et al. Oral administration of probiotics inhibits absorption of the heavy metal cadmium by protecting the intestinal barrier. Appl Environ Microbiol. 2016;82:4429-4440.

11. Bonyadi F, Nejati V, Tukmechi A, et al. An investigation of the complex effects of a Saccharomyces cerevisiae cytoplasmic extract on apoptosis in K562 cells. Iranian Red Crescent Medical Journal. 2017;19:1-9.

12. Sriwongsitanont S, Ueno M. Effect of freeze-thawing process on the size and lamellarity of peg-lipid liposomes. The Open Colloid Science Journal. 2010;4:1-6.

13. Ernst 0, Zor T. Linearization of the Bradford protein assay. Journal of Visualized Experiments. 2010:e1918:153.

14. Ayoola S, Ajani E, Fashae O. Effect of probiotics (Lactobacillus and Bifidobacterium) on growth performance and hematological profile of Clarias gariepinus juveniles. World Journal of Fish and Marine Sciences. 2013;5:1-8.

15. Brunt J, Austin B. Use of a probiotic to control lactococcosis and streptococcosis in rainbow trout, Oncorhynchus mykiss (Walbaum). Journal of Fish Diseases. 2005;28:693-701.

16. Ferguson R, Merrifield DL, Harper GM, et al. The effect of Pediococcus acidilactici on the gut microbiota and immune status of on-growing red tilapia (Oreochromis niloticus). Journal of Applied Microbiology. 2010;109:851-862.

17. Newaj-Fyzul A, Adesiyun AA, Mutani A, et al. Bacillus subtilis $\mathrm{AB} 1$ controls Aeromonas infection in rainbow trout (Oncorhynchus mykiss, Walbaum). Journal of Applied Microbiology. 2007;103:1699-1706.

18. Zhou J, Shu Q, Rutherfurd K, et al. Safety assessment of potential probiotic lactic acid bacterial strains Lactobacillus rhamnosus HN001, Lb. acidophilus HN017, and Bifidobacterium lactis HN019 in BALB/c mice. International Journal of Food Microbiology 2000;56:8796.

19. Hogan G, Adams D. Lead-induced leukocytosis in female mice. Archives of Toxicology. 1979;41:295-300.

20. Mugahi MN, Heidari Z, Sagheb HM, et al. Effects of chronic lead acetate intoxication on blood indices of male adult rats. DARU Journal of Pharmaceutical Sciences. 2003;11:147-151.

21. Dongre NN, Suryakar AN, Patil AJ, et al. Biochemical effects of lead exposure on systolic \& diastolic blood pressure, heme biosynthesis and hematological parameters in automobile workers of north Karnataka (India). Indian Journal of Clinical Biochemistry. 2011;26:400-406.

22. Hegazy AA, Zaher MM, Abd el-hafez MA, et al. Relation between anemia and blood levels of lead, copper, zinc and iron among children. BMC Rsearch Notes. 2010;3:19. 
23. Haya J, García A, López-Manzanara C, et al. Importance of lactic acid in maintaining vaginal health: a review of vaginitis and vaginosis etiopathogenic bases and a proposal for a new treatment. Open Journal of Obstetrics and Gynecology. 2014;4:787-799.

24. Golalipour MJ, Roshandel D, Roshandel G, et al. Effect of lead intoxication and D-penicillamine treatment on hematological indices in rats. International Journal of Morphology. 2007;25:717-722.

25. Helmy M, El-Naga N, Helal S. Effect of administration of milk and Kareish cheese on hematological values and histological changes of liver and brain in rats treated with lead. Alexandria Journal of Agricultural Research. 2000;45:103-118.

26. Khan M, Mostofa M, Jahan M, et al. Effect of garlic and vitamin b-complex in lead acetate induced toxicities in mice. Bangladesh Journal of Veterinary Medicine. 2008;6:203-210.
27. Amjad Z, Iqbal MZ, Shoro AA. Lead-induced reduction in body and kidney weight of Wistar albino rats ameliorated by Ginkgo biloba extract (EGb 761). Biochem Physiol. 2013;2:1-4.

28. Ruiz S, Espín S, Rainio M, et al. Effects of dietary lead exposure on vitamin levels in great tit nestlings - An experimental manipulation. Environmental Pollution. 2016;213:688-697.

29. Finger A, Lavers JL, Dann P, et al. Metals and metalloids in Little Penguin (Eudyptula minor) prey, blood and faeces. Environmental Pollution. 2017;223:567-574.

30. Djurasevic S, Jama A, Jasnic $\mathrm{N}$, et al. The protective effects of probiotic bacteria on cadmium toxicity in rats. Journal of Medicinal Food. 2017;20:189-196.

31. Rayes AA. Field studies on the removal of lead, cadmium and copper by the use of probiotic lactic acid bacteria from the water for culturing marine tilapia T. spilurus. New York Science Journal. 2012;5:74-82. 